\title{
Metal and Stone, Brush and Ink: Word as Source in the Art of Huang Binhong
}

\section{Claire Roberts, University of Adelaide}

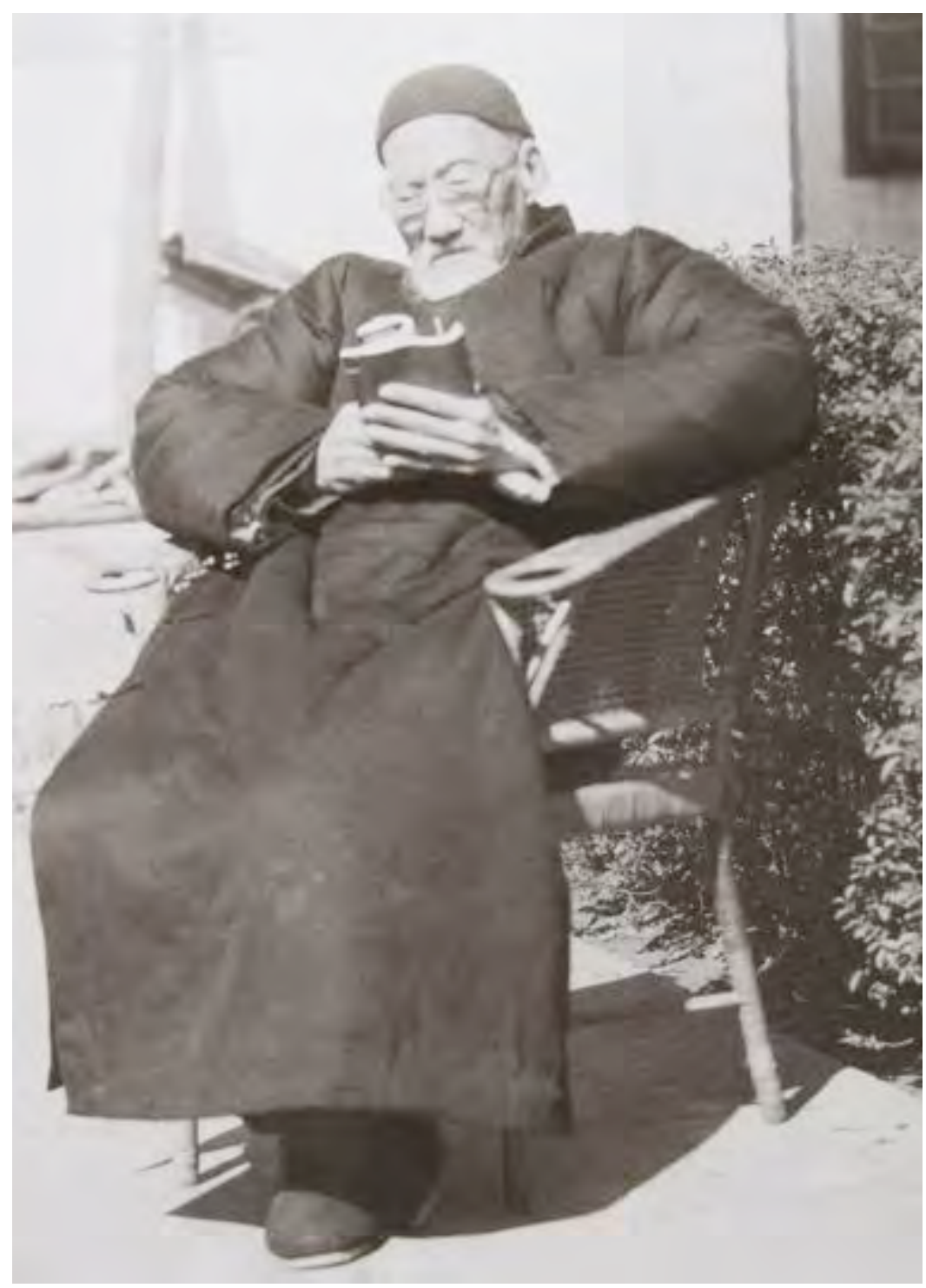

Figure 1: Photo of Huang Binhong reading at home in Hangzhou. [Reproduced in Huang Binhong quanji (2006: vol. 10, 289)]

PORTAL Journal of Multidisciplinary International Studies, vol. 9, no. 3, November 2012. Politics and Aesthetics in China Special Issue, guest edited by Maurizio Marinelli. ISSN: 1449-2490; http://epress.lib.uts.edu.au/ojs/index.php/portal PORTAL is published under the auspices of UTSePress, Sydney, Australia. 
In 1948, on the eve of the fall of Beiping to Communist forces, scholar-artist Huang Binhong (黃賓虹 1865-1955), then aged 85 and widely regarded as one of the greatest Chinese landscape painters of the twentieth century, travelled by aeroplane to Shanghai, and then overland to Hangzhou. The journey marked the end of a decade of living in the former imperial capital, much of it under Japanese occupation. ${ }^{1}$ Huang's son-in-law carried the artist's most precious belongings as hand luggage: a sack of 900 ancient seals and a roll of historic paintings cut from their wooden rods to lighten the load, treasures from his personal art collection. Today, Huang Binhong's historic seals and paintings, as well as a large archive of his own paintings, calligraphy and personal papers, are core collections of the Zhejiang Provincial Museum, Hangzhou.

Huang's multiple identities, as artist, scholar, collector and connoisseur were integral to his creative practice (Roberts 2010: 52-53). Like many of his contemporaries born in the late nineteenth century (at the end of the Qing dynasty) he received a classical

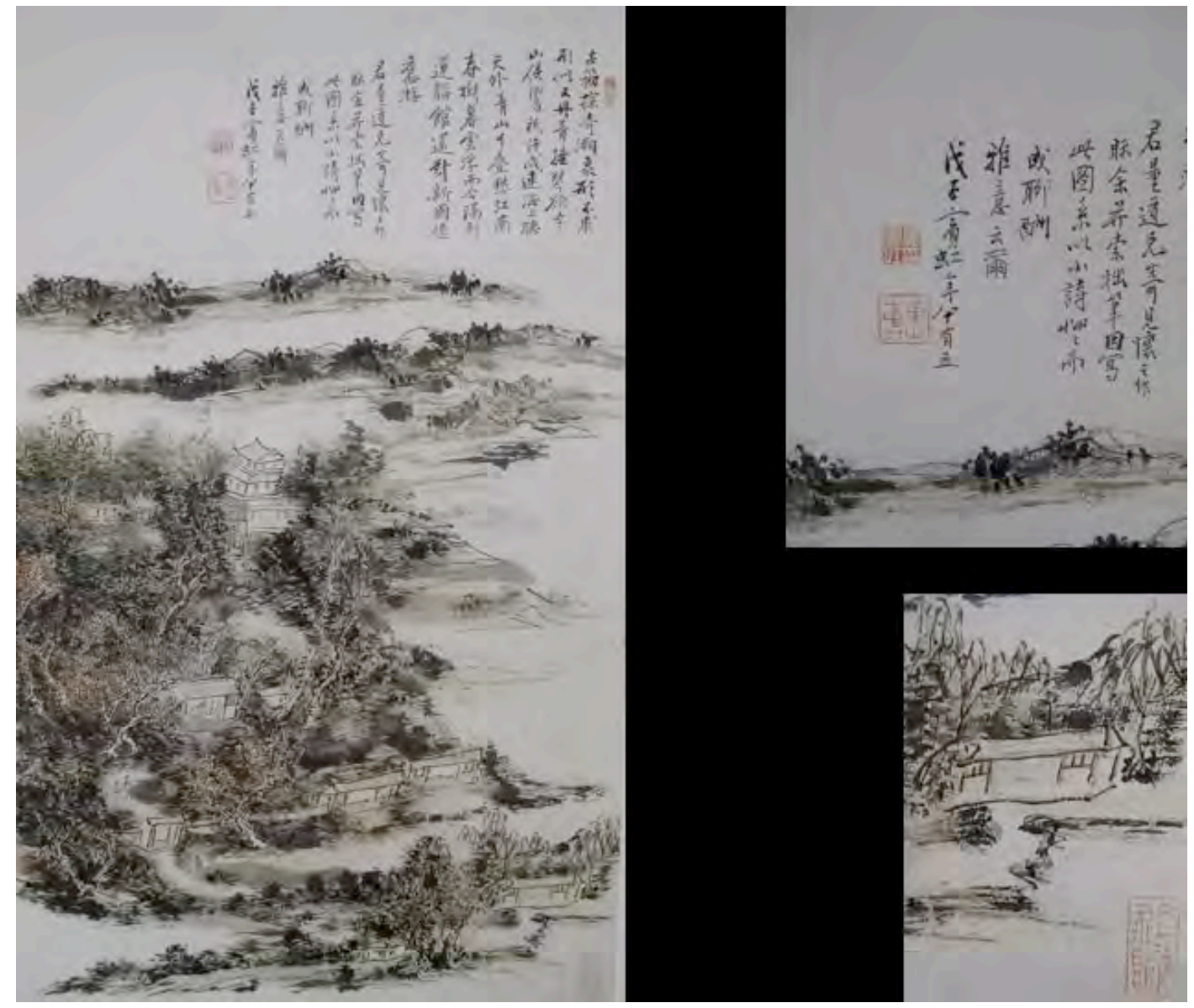

Figure 2: Huang Binhong, hanging scroll, Landscape, ink and colour on paper, 1948. [Reproduced in Huang Binhong quanji (2006: vol. 10, 257)]

\footnotetext{
${ }^{1}$ For background on Huang Binhong's period of residence in Beiping, see Roberts (2007).
} 
education with deep foundations in historical, text-based learning. In the case of Huang Binhong, that learning engendered creative expression in the form of painting, calligraphy and seal carving, and scholarly expression in the form of art historical research and collecting. While based on cultural traditions of the past, calligraphy and painting were a means to mediate the present and imagine the future. They were the expressive embodiment of the artist who was vitally connected to the historical past.

The written word is central to Chinese brush-and-ink painting in a way that it is not in most Western art. The same brush is used for calligraphy and painting; artists 'write' rather than paint a painting; and text is an integral part of any work: a poetic inscription is usually added to a painting, sometimes with a dedication to the person it is being created for, together with the artist's signature, a date and the artist's seal. In a painting dedicated to Low Chuck-tiew (劉作籌 1911-1993) that dates from 1948, three of the four seals were carved by Huang Binhong. ${ }^{2}$ The uppermost seal 'Huang Binhong's seal' (Huang Binhong yin 黄賓虹印) was engraved directly into the stone, whereas the other two seals, 'Hermit of Mount Huang' (Huangshan shan zhong ren 黄山山中人) and 'Studio of the Wild Swan Flying Over Ice' (Bing shang hong fei guan 冰上鴻飛館) were created through a reverse process of cutting away stone to reveal the characters, so that the seal impression appears as red characters against a white ground. Seals are works of art in miniature and require considerable epigraphic and compositional skill. Their role within a painting is to enhance compositional balance, confer authenticity and signal completion of the artistic process. When a seal is impressed onto a painting it contrasts with the fluid expression of the calligraphic brushwork creating a tension between the temporal and the spiritual, the past and the present, word and image. Together, the different elements of a painting create a whole, its layers and references intended to be read and deciphered like a text, and its visuality understood within a lineage of scholarly art practice.

Through his activity as a collector and his prodigious output as a scholar and connoisseur, the art of Huang Binhong highlights the deep literary and historical resonances that continued to operate within the scholarly arts of painting and

\footnotetext{
${ }^{2}$ See Huang Binhong quanji 1 (2006: 298).
} 
calligraphy into the twentieth century. ${ }^{3}$ In the pages that follow I will consider the centrality of place and learning in Huang Binhong's art and how the past and the present co-exist in ways that open up artistic practice and make it possible to conceive of his paintings as being at once rooted in the past and actively engaged in a spirit of enquiry to create a new and expressive artistic language that was distinctively his own.

\section{Place as source: Jiangnan, Shexian and Huangshan}

Huang Binhong identified with the landscape and artistic traditions of Jiangnan 江南 the lower Yangtze River valley. In particular it was his ancestral home of Shexian in Anhui, and the region that encompassed Jinhua, Hangzhou, Huangshan (Yellow Mountain) and the Yangtze and Xin'an rivers. It was here that Huang Binhong spent formative years of his life. Historically, it was the cultural heartland of China with a concentration of well-educated scholar-gentry families, who had amassed important collections of books and artworks. ${ }^{4}$ Throughout his life Huang Binhong drew intellectual and artistic inspiration from the landscape of southeastern Anhui and Huangshan and the many artists, poets and scholars in whose footsteps he followed.

Shexian is renowned for its great concentration of mountains and waterways. It is defined by mountains: Huangshan to the northwest, Tianmushan to the Northeast and Baijishan to the Southwest. During the Ming and Qing dynasties it became a great mercantile centre, owing to its strategic location at the confluence of numerous waterways that linked Anhui with Zhejiang and Jiangsu. Shexian was famous for local products including the 'Four Treasures of a Scholar's Studio' (Wenfang sibao 文房四寶): ink, paper, brushes and ink stones.

Huang Binhong's ancestor Huang Cisun, a scholar of the Imperial Academy, was one of a number of natives from Shexian who achieved success in the imperial examinations. The Shexian Gazette credits the beauty of the natural environment, together with the tenacity and ingenuity of the local people, for the creation of merchant wealth and the nurturing of many fine scholars and artists (Shexian zhi 1995: 503-5, 577-79). Shexian was a place of austere beauty where business, education and art were inextricably linked.

\footnotetext{
${ }^{3}$ See the six volumes of Huang Binhong's writings, Huang Binhong wenji (1999), which include his scholarship on ancient seals, art history, and connoisseurship.

${ }^{4}$ In a short essay written in a supplement to Shenzhou ribao and published sometime between 1913 and 1914, Huang Binhong provided information about some of the major collectors in Shexian from the Ming dynasty through to the early twentieth century. See Huang Binhong wenji (Zazhu bian) (1999: 67).
} 
The manufacture of the tools and materials used by scholars to write and paint, quality goods that also appealed to court officials and local scribes, drew on the local resources of the area - pine trees, bamboo, clean water and high quality stone. Historical records indicate that high quality ink made from pine soot, inkstones and paper, had been produced in Shexian since the Tang dynasty (Berliner 2003: 11-12). In 1890, Huang Binhong himself gained first-hand experience in making ink, when he helped his father manufacture ink as part of a business venture that the family developed in response to poor quality imports and out of a desire to revive the local industry (Wang Zhongxiu 2005: 24). The business was abandoned following his father's death in 1894, but Huang retained a highly developed appreciation of fine ink. ${ }^{5}$

The presence of abundant supplies of timber attracted skilled carvers and contributed to the growth of high-quality wood carving workshops in Shexian. Local timber was used to make wood blocks for printing books and carved wooden moulds for ink sticks that were both practical and prized by collectors. Creative collaborations between scholars, artists, artisans and entrepreneurs produced high quality illustrated books. ${ }^{6}$

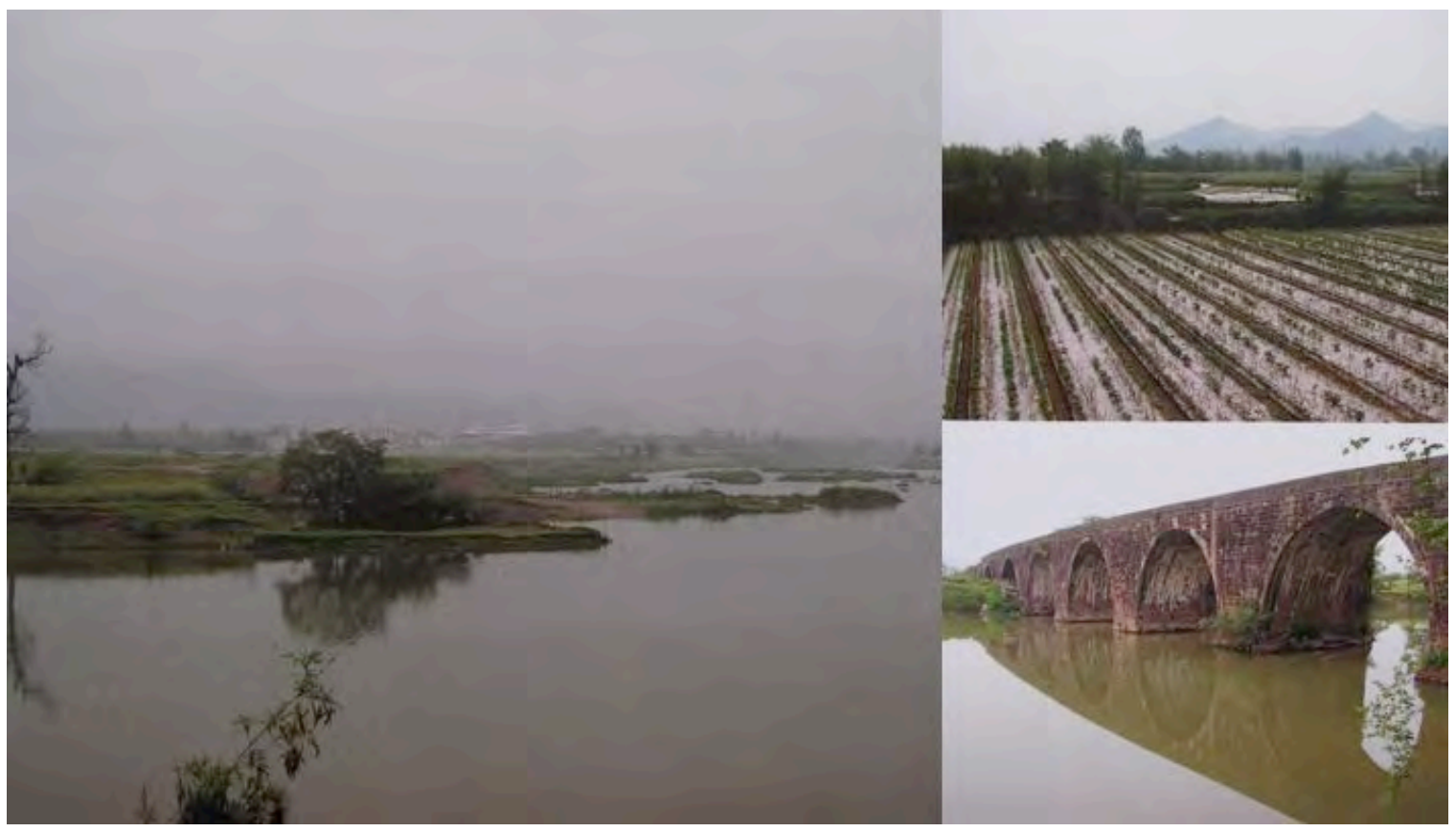

Figure 3: Photos of Tandu village and site of the Binhong Pavilion.

[Photographs (C) Claire Roberts]

\footnotetext{
${ }^{5}$ Huang Binhong published a detailed essay on the history of ink making ' $X u$ zao mo' in the Shanghai journal Guocui xuebao (volumes 42 and 44, 1908), which drew on this experience and subsequent research. See Huang Binhong wenji (Zazhu bian) (1999: 13-20).

${ }^{6}$ For an overview of woodblock printing in Shexian, see Kobayashi and Sabin (1981: 25-32).
} 
One of Huang Binhong's early, published writings is an essay entitled 'Village Living'? In it he speaks of the close relationship between the Huang family and Tandu village (潭 渡村) in Shexian. Tandu takes its name from the place where a deep pond (tan 潭) must be crossed ( $d u$ tan 渡潭): in the Tang dynasty the Huang family moved to Huang tun, which was nine $l i$ west of Shexian, just north of the point where where the pond is crossed. $^{8}$

In the essay Huang lists the mountains that surround the ancestral village and the rivers, streams, lakes and deep ponds. ${ }^{9}$ He describes the 'Pavilion of the Rainbow at the Water's Edge' or Binhong Pavilion (Binhong ting 濱虹亭) on the northern bank of the stream, as one of the most beautiful spots in Tandu, from where he would derive his artist name, Binhong 濱虹. ${ }^{10}$ The landscape he evokes, part real, part imagined, draws on an idea of the past, inspired by literary remnants, family lore and natural and architectural features that survived the vicissitudes of time.

The essay is an intimate portrait of the ancestral home that he was in the process of leaving. After moving to Shanghai in 1909 he would never return to live in Shexian. Yet the mountains and waterways of area were to remain an important inspiration for his art, poetry and writing for years to come. Huang Binhong's essay takes on a more polemical significance if it is considered as part of a genre of writing about historic places and homelands that developed in response to anti Manchu-Qing nationalism, modernisation and westernisation. It was published in the Journal of the National Essence in 1908 three years before the 1911 revolution that would bring the 'foreign' Manchu-Qing dynasty to and end.

Huang's research into family history and the intimate portrait of Tandu village is similar to undertakings conducted in other parts of the world at this time. One example is Dinesh Chandra Sen (1866-1939), a Bengali scholar, historian and devotee of Bengali literature, who was a contemporary of Huang Binhong. Sen scoured the East Bengal countryside for old manuscripts. Dipesh Chakrabarty describes Sen's work as 'romantic

\footnotetext{
${ }^{7}$ The essay was originally published in 1908, Guocui xuebao, volumes 42 and 43. See Huang Binhong wenji, zazhu bian (1999: 7-12).

${ }^{8}$ Huang Binhong wenji (Za zhu bian) (1999: 422).

${ }^{9}$ The mountains surrounding Tanducun are cited as Taishoushan and Xieshan to the northwest, Fengshan, Jingtangshan to the south, Lingshan, Jinlanshan, Huangluoshan and Tianmashan to the west and the famous Huangshan or Yellow Mountain to the north. Huang Binhong wenji (Zazhu bian) (1999: 7).

${ }^{10}$ Huang Binhong wenji (Za zhu bian) (1999: 8).
} 
anti-colonial nationalism':

For those who, like Sen and others of his generation, had seen literature as quintessentially political, the past was constituted, ultimately, not merely by historical evidence but also by emotional and experiential recollections of the past. The past in that sense could fuse with the present. It was inhabitable in spirit. Sentiments and emotions were thus a part of the method of both constituting and accessing a collective past. (Chakrabarty 2004: 167)

For Huang Binhong, like Sen, the evocation of place was an expression of both a personal identity and a nascent national spirit, with a political dimension at a time of tension and change.

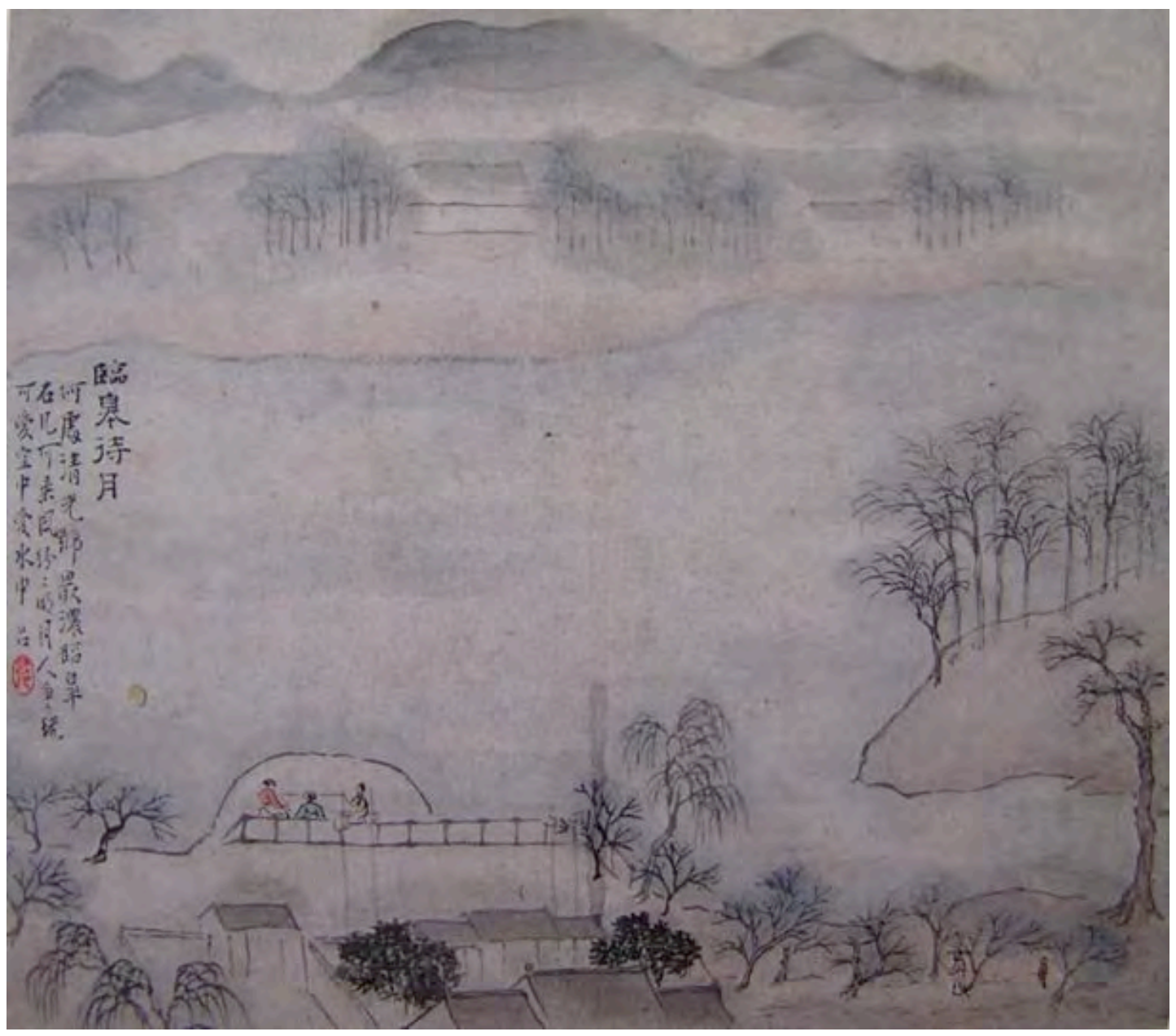

Figure 4: Huang Lü, album leaf, Eight Views of Tandu, ink and colour on paper, early 1700s.

[Collection: Zhejiang Provincial Museum, Hangzhou]

An album titled 'Eight Views of Tandu' (Tandu ba jing 潭渡八景) painted by Huang Binhong's ancestor Huang Lü (黄吕) in the early 1700s and acquired by Huang in 1928 is a fine example of his use of historical collections to access a personal and a collective past. Huang Lü was the son of Huang Sheng (黄生 hao Baishan 白山, 1622-1696), a literatus and Ming loyalist. Huang Lü studied with his father and was skilled in the 'four 
arts' of poetry, painting, seal carving and calligraphy, as well as martial arts. He continued his father's interest in family history and published Miscellaneous Annals from Tanbin, a book which greatly influenced Huang Binhong's own interest in family and local history. ${ }^{11}$

The 'Eight Views' depict life in the ancestral village and its situation on wide river flats at the confluence of numerous waterways. Each leaf is accompanied by a twenty-eight character poem. The album opens with a painting entitled 'Waiting for the moon by the bank of the river.'

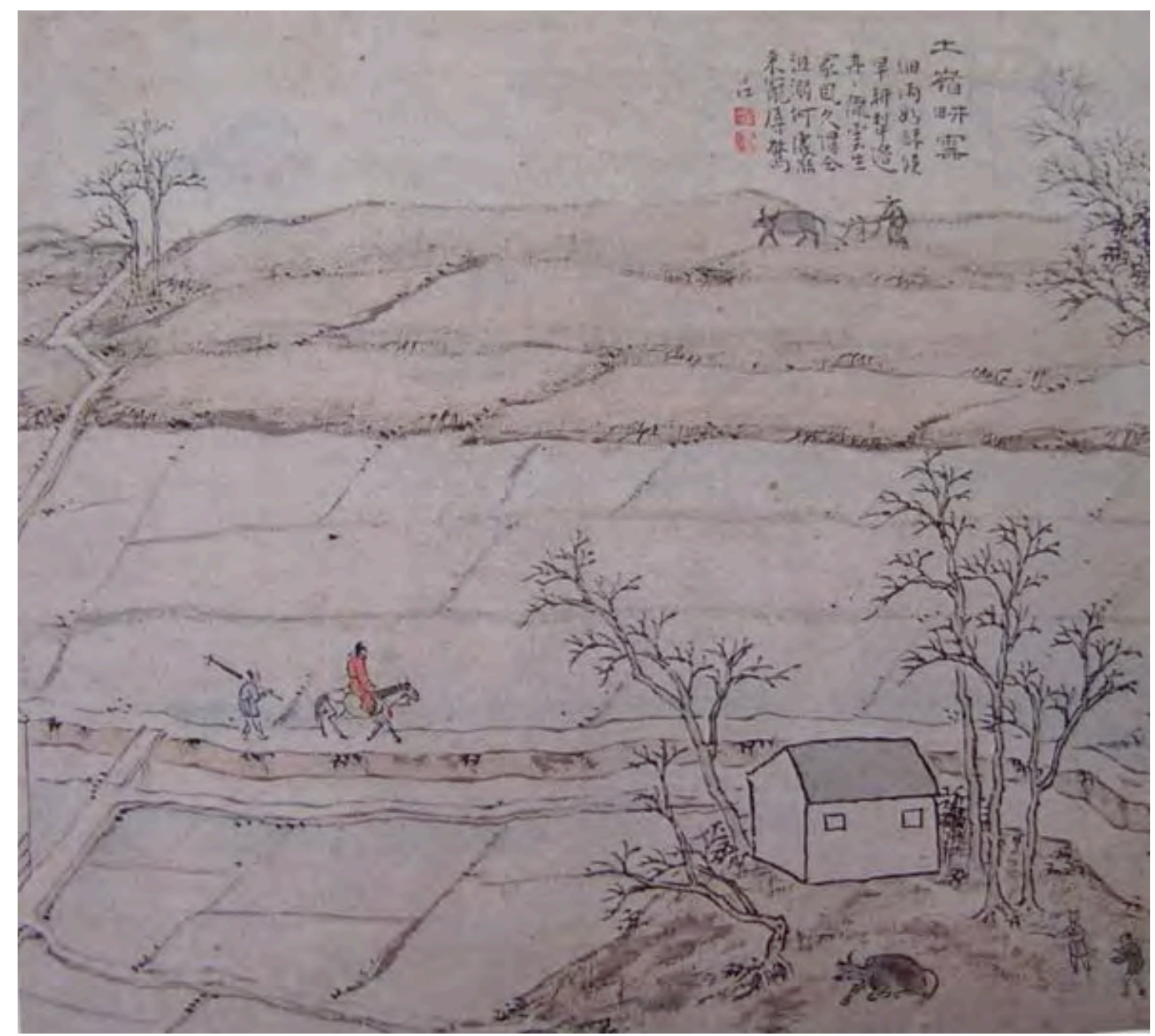

Figure 5: Huang Lü, album leaf, Eight Views of Tandu, ink and colour on paper, early 1700s. [Collection: Zhejiang Provincial Museum, Hangzhou]

The second leaf depicts an agricultural scene and the incongruous figure of a scholar on horseback, drawing attention to the large number of educated men who came from the area. The album held a particular significance for Huang Binhong who, during an

${ }^{11}$ Tanbin was an early name for Tandu. 
extended period of cultural and political turmoil, was exploring and locating his identity in his homeland and the cultural world of his forebears.

\section{Huangshan: paintings and name seals}

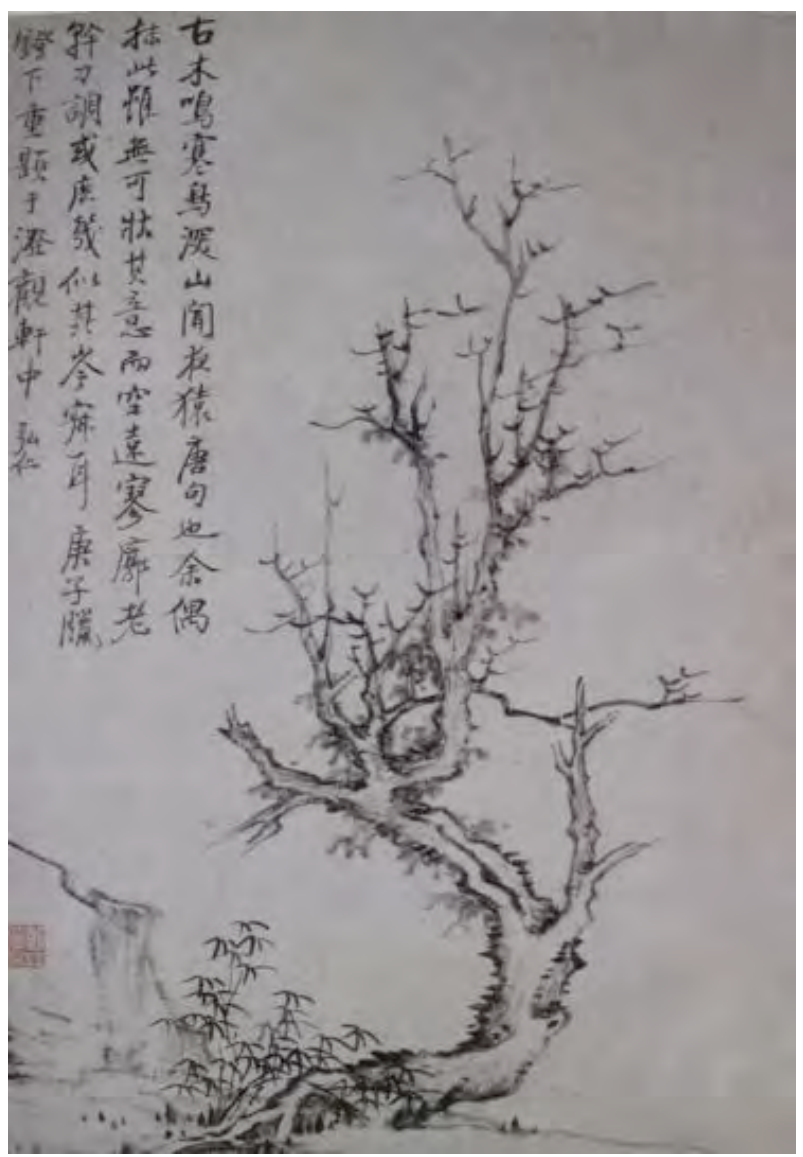

Figure 6: Hongren, hanging scroll, Ancient tree, ink on paper, 1669.

[Collection: Zhejiang Provincial Museum, Hangzhou]

Huang Binhong's fascination with Shexian and Huangshan was complex and multifaceted, at once literary, visual and experiential. His identification with Huangshan is highlighted in signatures on paintings and references to his collection: 'Hongruo from below Tiandu Peak of Huangshan’ (Huangshan Tiandu xia Hongruo 黄山天都下虹若) and 'from the collection of Huang Binhong's studio at Tiandu' (Tiandu Huang Binhong 天都黄賓虹). ${ }^{12}$ Tiandu refers to the Heavenly Citadel Peak (Tiandufeng 天都峰) of Huangshan and alludes to the Tiandu School which was synonymous with the Huangshan or Xin'an school of artists.

\footnotetext{
${ }^{12}$ Paintings from Huang Binhong's collection were reproduced in the art supplement Jinshi shuhua in 1936 and 1937 (Yu Shasong 1988). For example Jinshi shuhua, 65 (1936), p.2, and a painting dated 1936 now in the collection of the Arthur M. Sackler Gallery in Washington, DC (S1987.252). Hongren also expressed his identification with Shexian and Huangshan by sometimes signing his paintings with a reference to the names of temples or mountain peaks of Huangshan and environs. See Cahill (1981: 80).
} 


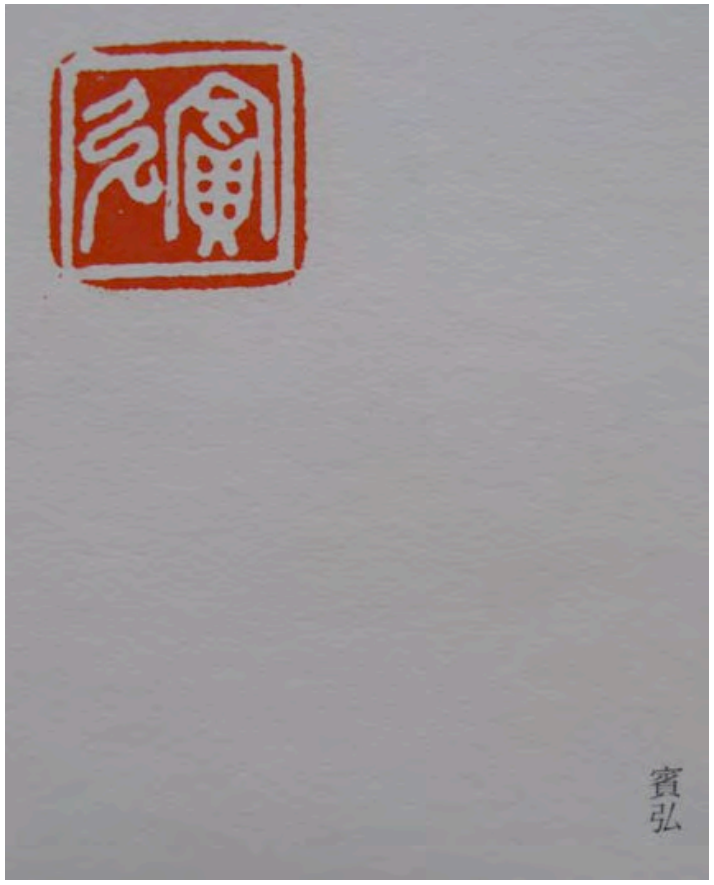

Figure 7: Li Yinsang seal - 'Binhong.'

[Collection: Zhejiang Provincial Museum, Hangzhou]

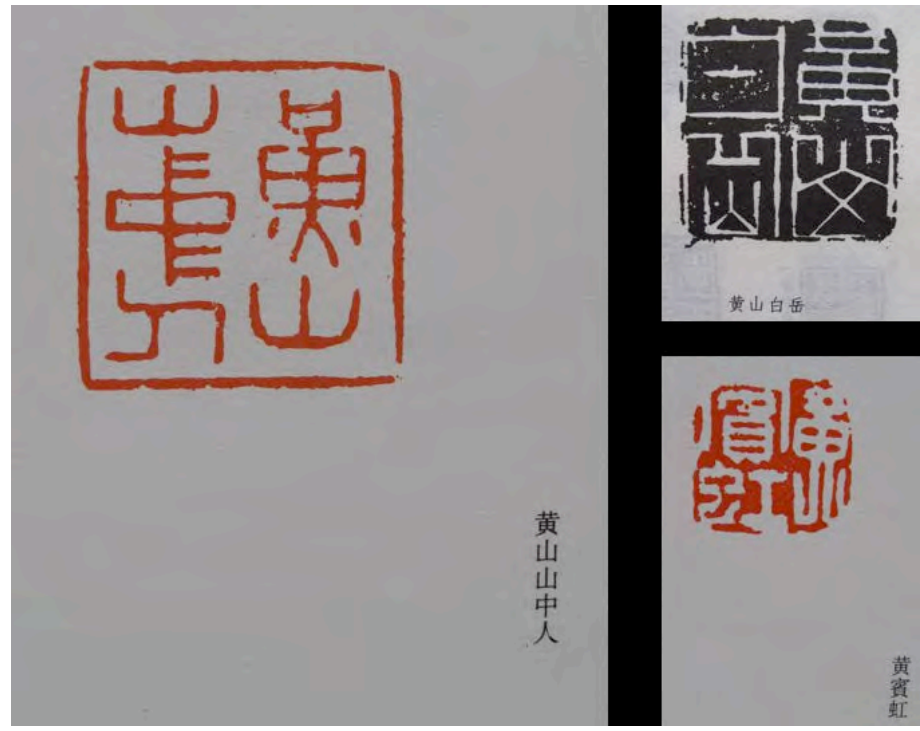

Figure 8: Huangshan name seals carved by Huang Binhong. [Collection: Zhejiang Provincial Museum, Hangzhou]

Huang Binhong developed his own considerable collection of paintings by Shexian and Huangshan artists. He had visited his relative, Huang Cisun (黄次孫) in 1882 the year before his death, and was given a number of paintings including a small painting by Hongren (弘仁). Huang Binhong admired Hongren as a fellow county man who identified strongly with Huangshan, as a Ming loyalist and as an artist who succeeded in creating an independent style. One of Huang Binhong's early seals, carved by Li 
Yinsang (李尹桑 1880-1945) features two characters that sound like the artists name Bin hong 賓弘. Hong means great or magnanimous and is the first character of Hongren's name. By using it, instead of the character for rainbow (hong 虹) found in Huang's own name, Li Yinsang suggests that for Huang Binhong, Hongren was the single most important artist of the Huangshan or Xin'an school.

Huangshan was originally called Ebony Mountain (Yishan 黟山). It is said that the Yellow Emperor travelled there to collect herbs for an elixir. In 747 Emperor Minghuang of the Tang dynasty, who was a practicing Daoist, changed the name of the mountain to Huangshan, thus linking it with the Yellow Emperor and Daoism. It is the name by which the mountain is known today.

Allusions to Huangshan and Daoism are frequent in many of Huang Binhong's artist names. Examples include a seal carved by Huang Binhong 'Hermit of Huangshan' (Huangshan shan zhong ren 黄山山中人), and a seal used by him in his middle years, Huang Binhong, that has been cleverly composed so that the character for mountain reads as the two lower strokes of the Huang character, which allows for the readings 'Huang Binhong' and 'Binhong of Huangshan' (Huangshan Binhong 黄山賓虹).

The names of the adjacent mountains, Huangshan and Baiyue, were combined in an early seal carved by the artist. The Jiajing Emperor of the Ming dynasty built the Palace of Ultimate Simplicity (Taisu gong 太素宫) on Mount Bai, which during its heyday supported more than one hundred Daoist temples (Wu Lixia 2003: 6-7).

Over the course of his life Huang Binhong made nine trips to Huangshan. The earliest was in 1883, at the age of twenty, and the last in 1935 when he was seventy-two.

Visible from his ancestral home, Huangshan was a place of great natural beauty. Aware of its Daoist and Buddhist associations, Huang would comment on the power of the mountain to sustain the soul and extend human life. ${ }^{13}$ The relative inaccessibility of the mountain, as well as the benefits that humans could derive from entering its reaches, had attracted scholars, artists, poets and recluses for centuries. By incorporating references to his native region, its history and its people into his painting, writing and seals, Huang Binhong created a rich and layered iconography of place.

\footnotetext{
${ }^{13}$ Huang Binhong wenji (Tiba bian) (1999: 82).
} 


\section{Collecting: Research and the preservation of national culture}

Throughout his life Huang Binhong spent what money he could afford on collecting seals, rubbings, books, painting and calligraphy. In his view connoisseurship, research, writing and painting were integral aspects of scholarly and artistic endeavour.

Seals made from stone or bronze were official accoutrements used to identify a person or an institution. They could be inscribed with a person's title, office or name, pen name or studio name (or poem or symbolic image) and were understood to embody the authority of the person or institution.

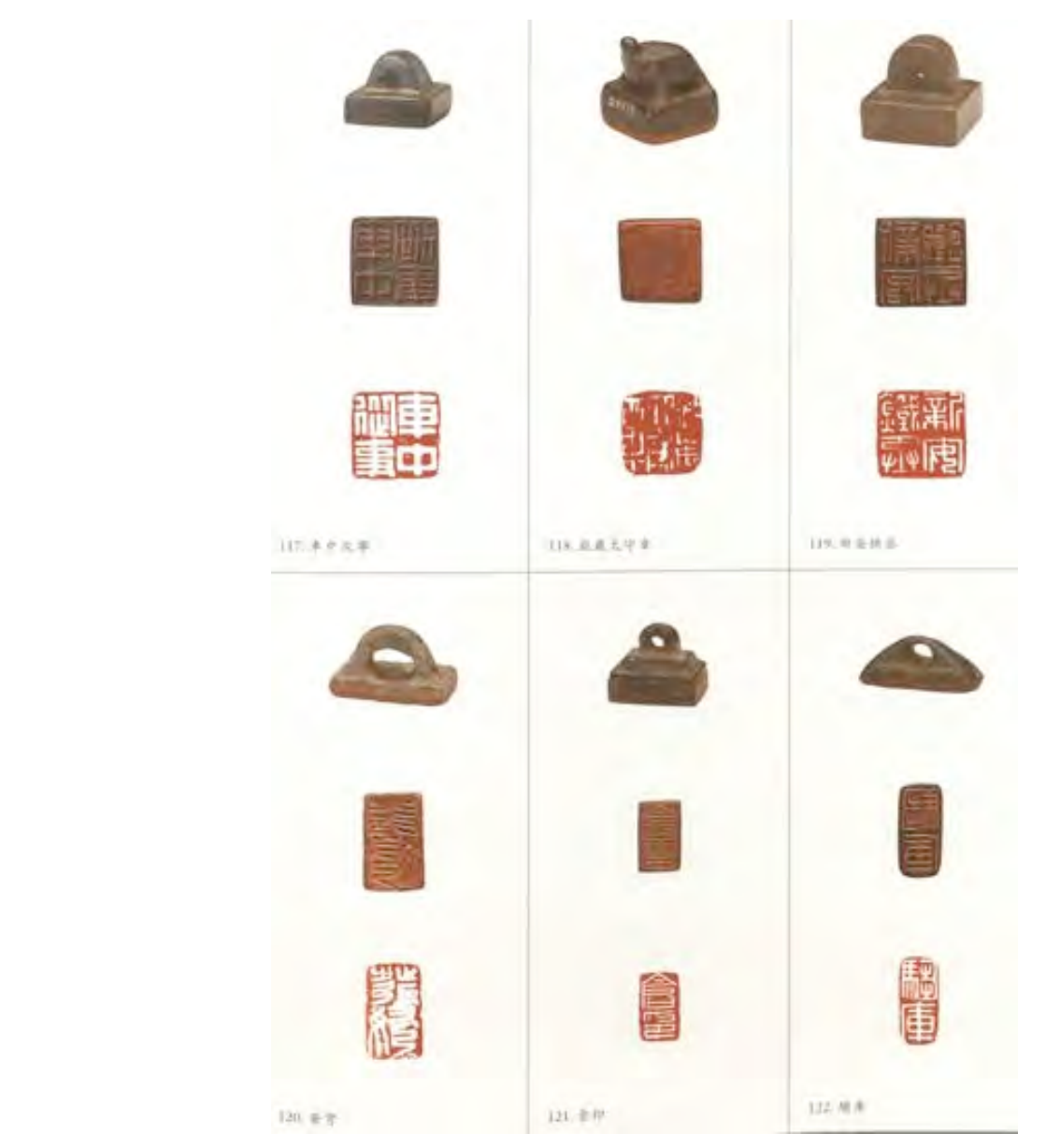

Figure 9: Ancient seals from Huang Binhong's collection now in the collection of the Zheijiang Provincial Museum, Hangzhou.

[Reproduced in Zhongguo lidai xiyin yishu (2000: 71)]

Huang Binhong's interest in collecting and researching ancient seals was connected to the broader cultural and political debate about the future of the Chinese language in the face of increased westernisation and modernisation. Those promoting full retention of the language argued that Chinese is one of the world's oldest written languages in continuous use and is fundamental to understanding the development of Chinese 
culture. The elevation of the written word to an art form and its integral relationship with painting meant that the appreciation of brush and ink painting could not be divorced from its relationship to the written word. Many scholars shared the belief that there was still much to be learned from an analysis of historical objects in circulation, such as ancient seals, as well as objects that were being recovered by archaeologists (Shan Guolin 1998: 31). ${ }^{14}$ The discovery of ancient inscribed fragments of tortoise shells and bones at the Shang-Yin (eleventh-twelfth century BCE) site near Anyang in Henan Province in the late 1800 s, for example, and the reproduction of many of those objects in magazines in the early 1900s, renewed intellectual interest in the debate over the antiquity and origin of the Chinese language (Yetts 1933: 657-85). ${ }^{15}$ Ancient words, inscribed on bone, cast in metal and incised in stone not only stimulated scholarly research but also exerted a profound aesthetic influence on seal carvers, calligraphers and painters.

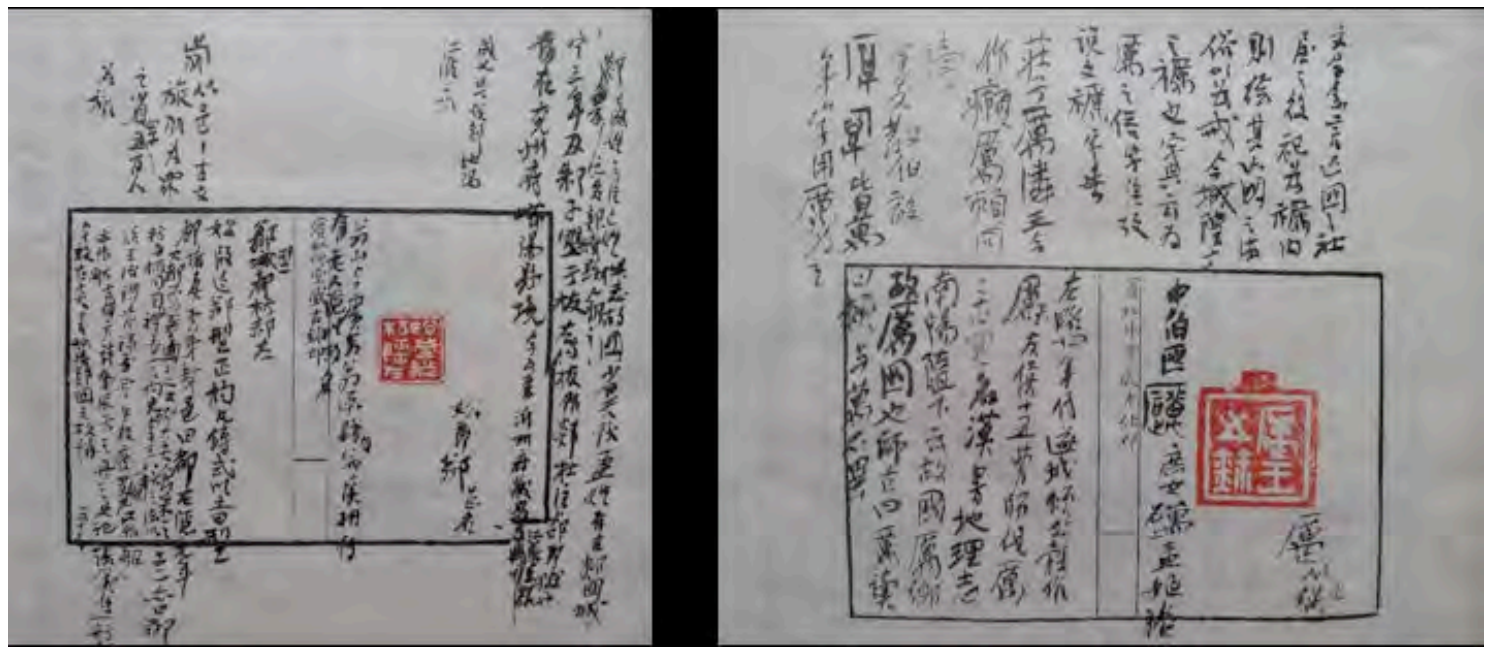

Figure 10: Pages from a book of Huang Binhong's collection of ancient seals: Binhong caotang cang guxiyin.

In 1883, at the age of 20, Huang Binhong was given a Han dynasty [206 BCE-220 CE] general's seal that originally formed part of a collection assembled by the bibliophile Wang Qishu（汪啓淑 1728-c.1799). Wang was from Shexian and a good friend of Huang Binhong's ancestor Huang Lü (who painted the Eight Views of Tandu). He had amassed a large collection of ancient seals and compiled many books on the subject,

\footnotetext{
${ }^{14}$ In the late eighteenth century calligraphers had begun to take an active interest in carved stone stele dating from the Six Dynasties period (317-589) that were excavated in large numbers. Similarly seal carvers began to take notice of ancient seals dating from the Qin and Han dynasties.

${ }^{15}$ See also Yetts (1933).
} 
reproducing the impressions of seals in his collection (Hummel 1943: vol. 2, 810-12). ${ }^{16}$ Huang saw many of Wang's writings on visits to Shexian and over time acquired a number of other seals that were originally part of the Wang Qishu collection. ${ }^{17}$

Huang Binhong's regard for learning from ancient objects that incorporated the written word was motivated by an intense curiosity to discover 'things never seen before':

\begin{abstract}
Whilst engravings on stone and bronze, calligraphy and painting are known as art they are in fact the mother of all skilled arts. They are second in importance after literature. Military force [ $w u$ 武] is used to suppress rebellions, words [wen 文] are used to govern. In former times $\square \square$ [denotes missing characters] until the Warring States period, civility had collapsed and music was destroyed, every day people were in search of weapons and warfare, people suffered and it was an extreme situation. But scholarship and culture remained as bright and luminous as ever and in the many thousands of years since then there is nothing to compare with it, the strangeness and extraordinary ability to engender a sense of wonder. I have searched for and collected ancient seals, numismatics, words impressed into pottery shards, things never seen before. The examination and recording of these objects has been gradually increasing ... It is important to study and appreciate [ancient] scripts and calligraphy as well as painting. If you learn from the best, then you will still only achieve something lesser. ${ }^{18}$
\end{abstract}

The objects that Huang acquired were appreciated for their philological and aesthetic dimensions, and as historic artefacts that were profoundly affected by the time in which they were created. After the widespread devastation of the Taiping wars, and subsequent political and social upheaval, scholars such as Huang Binhong believed that it was through the rediscovery of remnants of literary, visual and material culture that the new could be created.

\title{
Hangzhou: The late years
}

In 1948, soon after Huang's arrival in Hangzhou, an exhibition of paintings from his personal collection was displayed at the Hangzhou art academy. The inclusion of his own paintings with historic works of art underlines the close connection that he believed existed in his mind between the two. One of Huang Binhong's most beautiful works from this period is an album of paintings of Huangshan, dated 1949, painted for a friend from Shexian. ${ }^{19}$ The album may be thought of as marking his homecoming. While

\footnotetext{
${ }^{16}$ Wang's publications included Collection of Ancient Bronze Seals from the Han Dynasty (Han tong yin cong) printed in 12 volumes in 1755, and Qishu's Collection of Ancient Seals (Qishu ji gu yin cun) in 16 volumes.

${ }^{17}$ See Wang Zhongxiu (2005: 16, 20, 31) and 'Jiushi zashu, zhi yi', section one, in Huang Binhong wenji (Zazhu bian) (1999: 570-71). Impressions of the six seals were included in Wang's book Qishu ji gu yin qun. Huang Binhong wrote about Wang Qishu's collection of Han dynasty bronze seals in an article 'On a collection of ancient seals' (Xu gu yin tan), published in Xueshu shijie 1, no. 9 (March) 1936: 35.

${ }^{18}$ Huang Binhong, 'Zishu gao' in Huang Binhong wenji (Za zhu bian) (1999: 600). No date.

${ }^{19}$ Huang Binhong, Huangshan xiesheng ce (1997). See also Huang Binhong quanji 5 (2006: 170-88).
} 


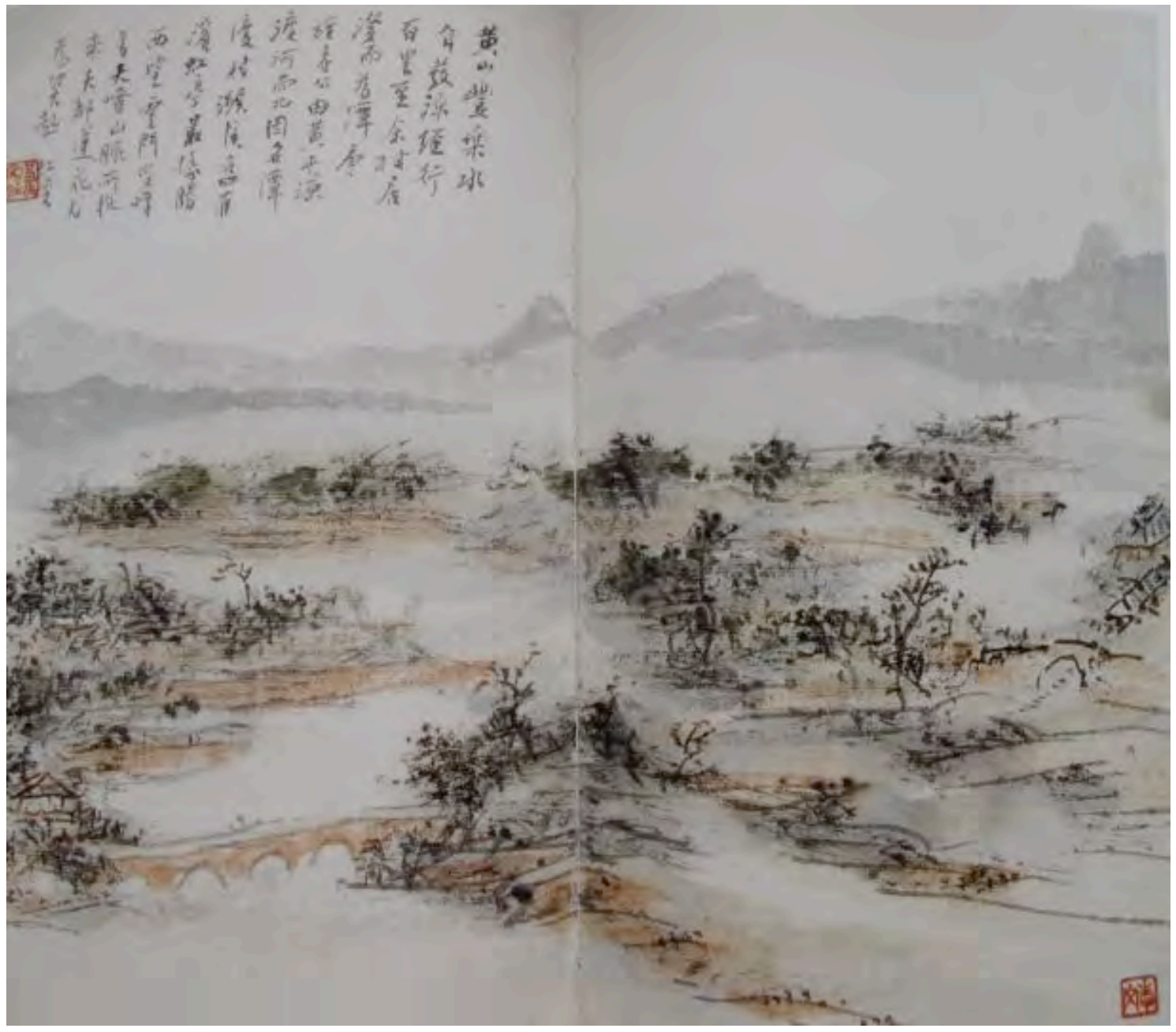

Figure 11: Huang Binhong, album leaf, Huangshan wo you album, ink and colour on paper, 1949. [Reproduced in Huangshan woyou: Huang Binhong quanji (2006, vol. 5: 176-77)]

Huang did not travel to Huangshan again, through painting he was able to return there in spirit. The title page is inscribed in seal script 'Travelling in Huangshan while remaining at rest' (Huangshan woyou 黄山臥游) and is followed by an introductory text written in a blunt cursive calligraphy: 'Every pine tree and rock in Cloud Valley has found its way into these paintings. The sound of a lute being strummed and the movement of someone exercising echo the sound of the mountains.' The album is intended to be read like a book. Paintings and poems written by Huang Binhong during his travels to Huangshan face one another on the page highlighting the interdependence of calligraphy, poetry and painting. In the middle of the album is a painting that continues across the two leaves, a misty, low-lying landscape executed with a dry brush and subtle colour washes. In the lower left corner there is a pavilion on the bank of a river, close to a large bridge that spans the waterway. Another bridge can be discerned to the right of the composition suggesting a complex river system. It is inscribed: 
The Fengle River travels some one hundred $l i$ from its source in Huangshan to my village where it gathers to form a deep pool. In the Tang dynasty, my ancestor Huang Chungong [Huang Rui] moved from Huangtun [黃屯]north to a point where you cross the deep pools, hence the name Tandu Village. In days gone by there was a Binhong pavilion, which was one of the most beautiful sites in the area. Looking west you can see the mountain range [of Huangshan], the two peaks of Cloud Gate [Yunmen 雲門] and Tiandu [Tiandufeng] and Lotus Flower Peaks [Lianhuafeng 蓮花 峰], the tallest of them all.

The autobiographical nature of the image and text provide an important context for understanding the album, which is suffused with memories of travel and personal experience.

According to an inscription, the images were gathered more than ten years earlier, probably during the last trip that Huang made to Huangshan in September 1935, with his wife Song Ruoying (宋若贞) and student Huang Bingqing (黄冰清) (Wang Zhongxiu 2005: 365-66). ${ }^{20}$ The paintings evoke a vivid mental landscape, and the delight of returning to southern China. They resonate with the feelings of elation and freedom on leaving the city and public office so famously expressed in Tao Yuanming's poem:

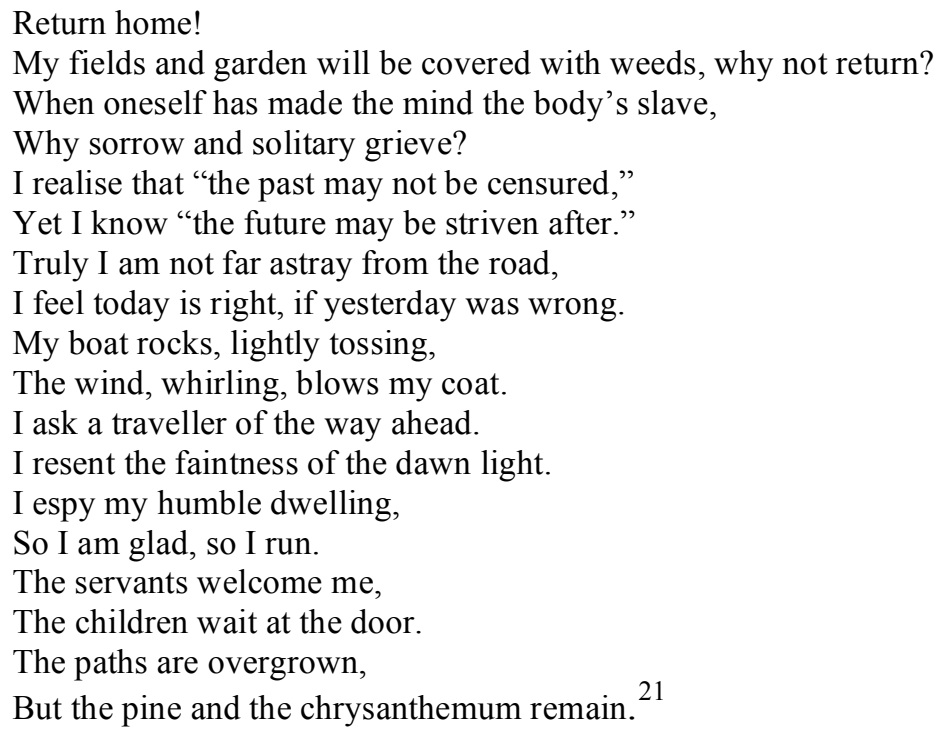

\section{Communist China: Challenges to culture}

In late 1951 Huang Binhong travelled to Beijing to attend the Third Meeting of the First National Committee of the Chinese People's Political Consultative Conference.

Ironically his presence at this meeting marks a turning point in the period of political and artistic limbo that he experienced from 1949 to 1951, and the beginning of his

\footnotetext{
${ }^{20}$ The party set out from Shanghai on 19 September 1935 and returned on 1 October. They also travelled to Tandu and Huangdun, and in Tangmo to view the calligraphy and painting collection of Huang's friend Xu Chengyao.

${ }^{21}$ Quoted in Barmé (2002: 220-21).
} 


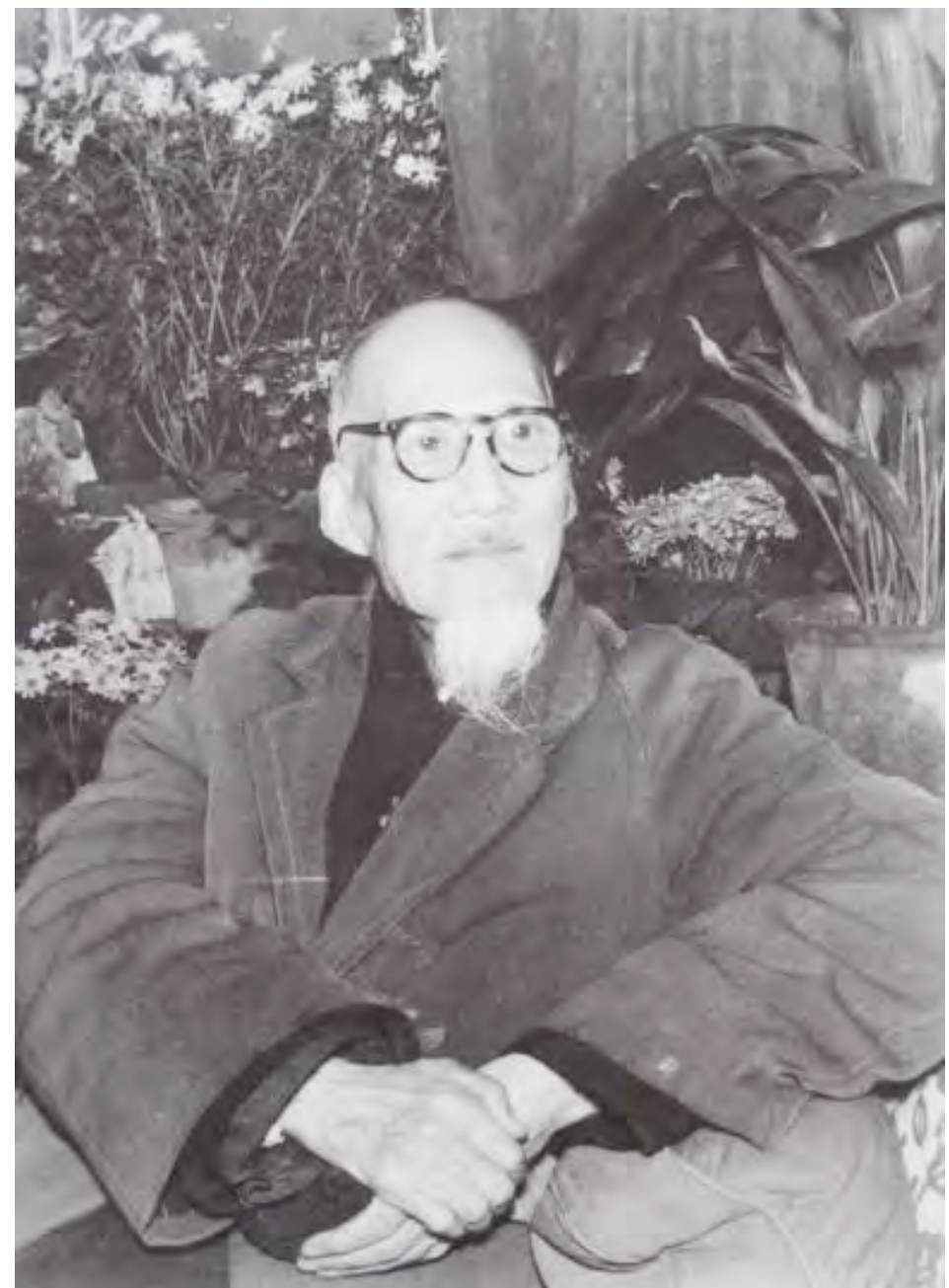

Figure 12: Photo of Huang Binhong taken in Beijing in 1951. [Reproduced in Huang Binhong quanji (2006: vol. 10, 268)]

recognition by Communist authorities at the national level. Huang was a specially invited public figure and participated in most of sessions of the week-long conference. ${ }^{22}$

He met and spoke with Mao Zedong (毛澤東 1893-1976), Chairman of the People's Republic of China, and had a long conversation with the Premier Zhou Enlai (周恩來 1898-1976). Mao Zedong apparently proposed a toast to Huang Binhong as the oldest of all the conference delegates and asked what he was working on. Huang replied that he was studying ancient inscriptions of the Warring States, to which Mao responded that he was currently reading non-canonical texts of the Zhou and Qin dynasties. ${ }^{23}$ Mao

\footnotetext{
${ }^{22}$ See Huang Binhong's identification card and book of tickets to be signed, dated and handed in when attending conference sessions. Eight tickets were used, and four remain unused. Collection of the Zhejiang Provincial Museum (ZPM 05644).

${ }^{23}$ See Xia Chengtao's dairy entry for early 1952, following a visit to see Huang Binhong, quoted in Wang Zhongxiu (1999: 526-27). Xia Chengtao was an academic and researched ci poetry of the Tang and Song dynasties. In 1952 Xia became head of the Chinese department at the Zhejiang Teacher's College (Zhejiang shifanxueyuan) in Hangzhou.
} 
Zedong, the iconoclast who brought radical political and cultural change to China was also a keen reader of ancient Chinese history and had an interest in Chinese poetry and literature. Transcriptions of historical poems in his distinctive calligraphic script came to be renowned, and he composed poems that had a strong classical flavour. ${ }^{24}$ The personal insight that Huang gained into Mao's interest in ancient Chinese literature and history, through their brief exchange, would have heartened Huang Binhong at a time when much traditional Chinese culture was under threat.

Two years later Huang Binhong dedicated a painting to Mao Zedong: 'The Chairman, Mr Runzhi, with wishes for a long life' (Runzhi xiansheng zhuxi shouqing 潤之先生主席 壽慶). ${ }^{25}$ In a customary way of expressing respect to a superior, Huang has placed Mao’s name higher than the rest of the inscription. The painting marks Mao Zedong's sixtieth birthday. In 1953 in the Huang Binhong turned ninety. A painting by someone of such advanced years was in itself symbolic of longevity. The painting is inscribed with a poem replete with historical allusions, and which praises Mao Zedong's leadership by linking Mao with $\mathrm{Yu}$, the legendary founder of the Xia dynasty, and China's classical past.

The legacy of the Great $\mathrm{Yu}$ is carved on Mount Heng Brilliant stars salute the northern heavenly body [Beidou, referring to Mao]. With a spirit descended from heaven, heaven responds by granting authority to rule, According to the [sixty-year] cycle of life there are reforms.

Drawing and painting pave the way for a flourishing cultural civilisation,

Boats and vehicles travel to virtuous neighbours.

Looking back on engravings in bronze and stone,

We join to wish you eight thousand springs.

The painting, signed Huang Binhong of Huangshan at the age of ninety, has a traditional tripartite composition. Mao Zedong would have delighted in the auspicious sentiments conveyed by the pairing of sail boats and pine trees which indicate smooth sailing and a long life. Huang's painting embodies the hope that many people held out for the new regime in the early years of the People's Republic of China. The elderly artist saluted Mao as a ruler with a mandate from heaven, highlighting at the same time the importance for Chinese civilisation of history, embodied by the inscriptions on bronze and stone, which he was researching.

\footnotetext{
${ }^{24}$ Mao Zedong's brush and ink calligraphy became ubiquitous in China. It could be found on newspaper mastheads, the name plaques of institutions and in the many books that were published to promote his ideology.

${ }^{25}$ Runzhi was Mao Zedong's pen name. See Zhongnanhai canghua ji (1993: vol. 1, plate 5). See also Huang Binhong quanji 4 (2006: 225)
} 


\section{Late Style: The inspiration of Dao-Xian (1821-1861)}

From 1952 to the end of 1954, Huang Binhong pursued an independent artistic style that had little to do with the subject matter and ideology promoted by the new Communist regime. The large volume of works he produced suggests a renewed interest in painting. He continued to take his inspiration from the art of the past, his travels in Sichuan and Guangxi, his ancestral home in Anhui and his new home by the West Lake in Hangzhou. His late paintings are shaped by his familiarity with brush and ink technique, the deterioration of his eyesight prior to a cataract operation in 1953 at the age of ninety, and a renewed vision.

Inscriptions on paintings from this period often refer to the art and calligraphy of the Daoguang (1821-1850) and Xianfeng (1851-1861) periods of the late Qing dynasty-

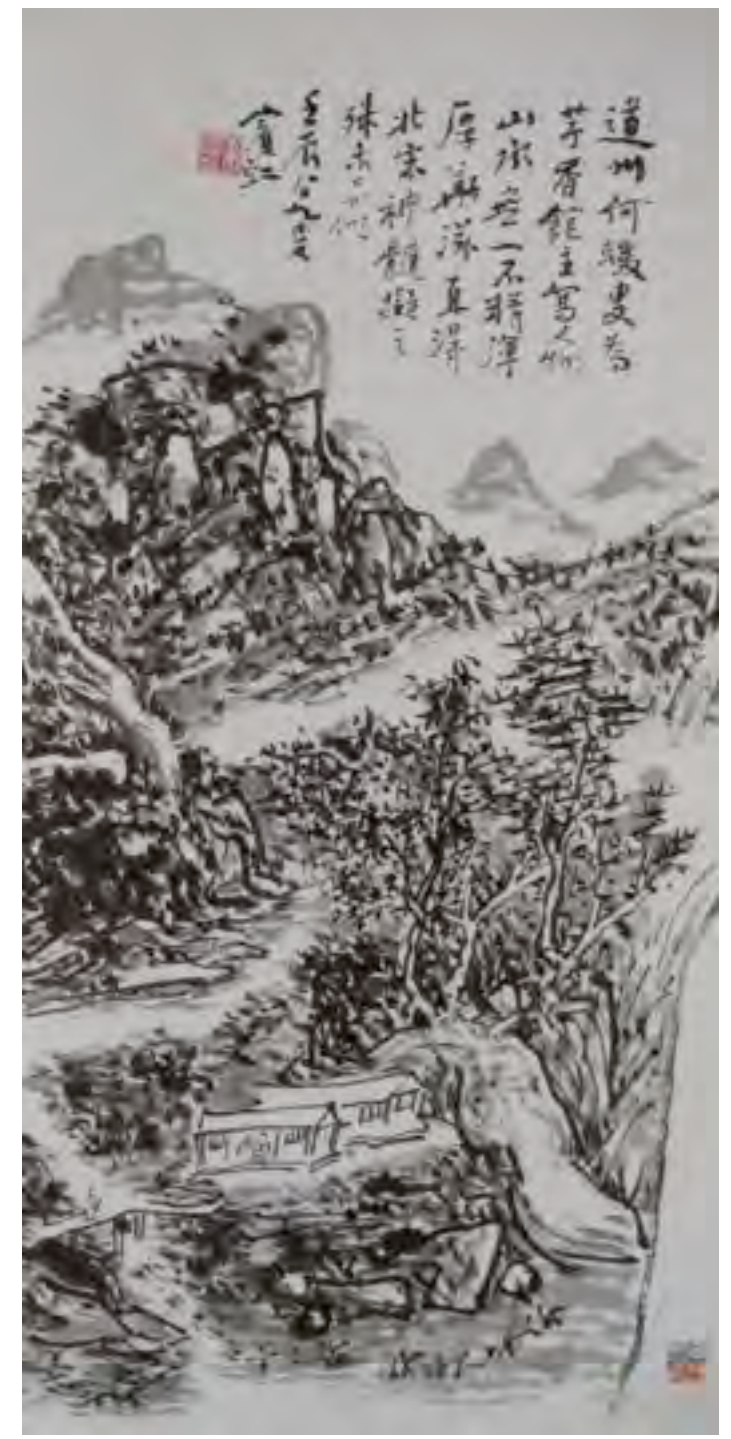

Figure 13: Huang Binhong, hanging scroll, Landscape, ink on paper, 1952

[Reproduced in Huang Binhong quanji (2006, vol. 2: 232)] 
the mid 1800s. Huang was attracted to the scholarly interest in epigraphy and the study of inscriptions on bronze and stone at that time, which led to the re-invigoration of calligraphy and painting. He identified with and championed the work of artists who lived one hundred years earlier on the basis of their ability to mediate and transform the art of the past. His concern to document artists who had slipped from public consciousness into obscurity perhaps also reflected his own extreme old age and a hope that a similar fate would not befall his own posthumous reputation.

In the inscription on a bold calligraphic painting Huang Binhong refers to the work of the late Qing calligrapher He Shaoji (何紹基 1799-1873) who created an individual style based the systematic study of ancient stone inscriptions (Chang et al. 2000: 66$69) .{ }^{26}$

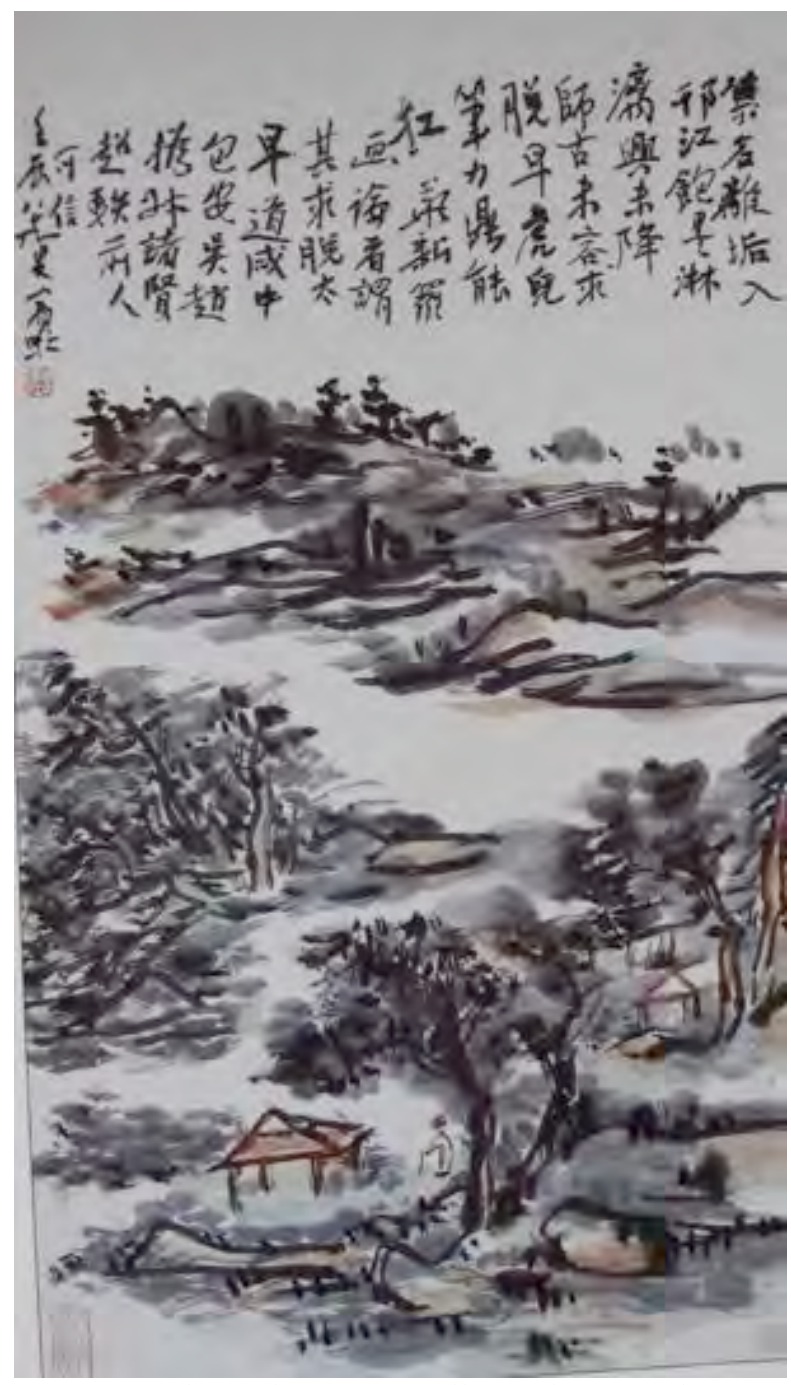

Figure 14: Huang Binhong, hanging scroll, Landscape, ink on paper, 1952. [Reproduced in Huang Binhong quanji (2006, vol. 3: 104)]

\footnotetext{
${ }^{26}$ See Huang Binhong quanji 2 (2006: vol. 2, 232).
} 
In a striking painting which exhibits an even freer and more abbreviated brush technique Huang refers to the brushwork of Hu'er [his ancestor Huang Sheng b. 1622], which he describes as being as 'powerful as a bronze [ceremonial vessel or] ding.' The inscription continues: 'I believe that Bao [Shichen], Zhao [Zhiqian] and other virtuous men of the Daoguang and Xianfeng periods did in fact surpass men of earlier times. ${ }^{27}$ Bao Shichen (包世臣 1775-1855) and Zhao Zhiqian (趙之謙 1829-1884), both active in the late $1800 \mathrm{~s}$, were important scholar-artists who developed individual calligraphic

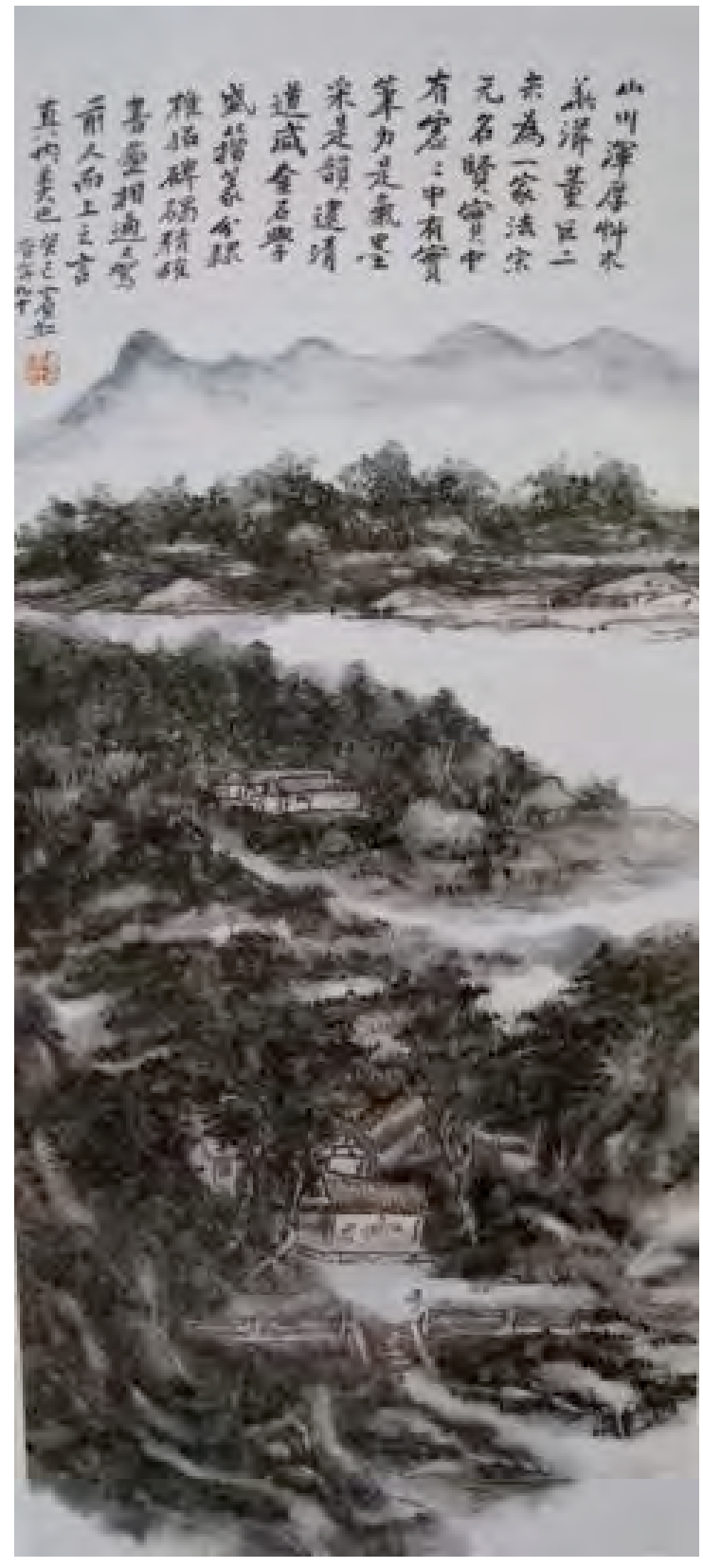

Figure 15: Huang Binhong, hanging scroll, Landscape, ink on paper, 1953

[Reproduced in Huang Binhong jingpin ji (2004: 64). Collection of the National Art Museum of China]

${ }^{27}$ See Huang Binhong quanji 3 (2006: vol. 3, 104). 
styles based on the study of early Chinese writing. Huang Binhong appreciated the practiced brushwork of calligraphers who turned their hand to landscape painting. ${ }^{28}$ In this work the calligraphic lines used for the painted elements and the inscription are similar, their volumetric form conveying an inner tensile strength. Huang's sure blunt brushstrokes painted with a splayed brush convey a feeling of 'metal and stone' derived from the study of ancient seals and inscriptions on stone stele and the careful balancing of elements within the painting suggest the resolution of areas of solid and void that occur in the creation of a seal. Through his powerful calligraphic abstraction of form and expressionistic use of ink and colour Huang Binhong demonstrates his own distinctive, transcendent style.

In an inscription on a quite different work, painted after his cataract operation, Huang gives us a summary of his philosophy of painting, based on a synthesis of ideas and techniques from the past.

\begin{abstract}
The mountains and rivers are solid and substantial and the grasses and trees lush and resplendent. The techniques of Dong [Yuan 董源], Ju [Ran 巨然] and the two Mi's [Mi Fu 米娋 and Mi Youren 米友仁] may be regarded as coming from the same school. [In the paintings of] famous artists of the Song and Yuan dynasties there is void within the solid and solid within the void. The force of the brush conveys life-breath and the colour of ink conveys resonance. During the Dao [Daoguang] and Xian [Xianfeng] periods of the Qing dynasty epigraphy flourished. Large Seal script, Small Seal script and Clerical script are distinct and were all used for text carved onto stone tablets. Truly great calligraphy and painting should combine the strengths of them all. These are the wise words of the Ancients. They represent true inner beauty. ${ }^{29}$
\end{abstract}

Huang Binhong refers to the concept of inner beauty (nei mei 內美), which he says may be found in the ancient scripts engraved in bronze and carved on stone. According to Huang inner beauty is a spirit or an aura the source of which lies within, 'in the bones'. It is a force that is concealed rather than overt, exerting a deep and lasting influence. ${ }^{30}$ The latent strength inherent in the brush strokes that derived from inscriptions carved into stone or cast in bronze, was for Huang Binhong the key to artistic renewal and the ultimate aesthetic.

\footnotetext{
${ }^{28}$ During the Daoguang period, Bao Anwu painted many landscape paintings for which he developed a following. See Zhongguo meishujia renming cidian (2004: 151-52). For other paintings by Huang Binhong with references to Bao Anwu's calligraphy and landscape painting, see Huang Binhong huaji (1985, plate 32); Huang Binhong huaji (1992, plate 25). For information on Zhao Zhiqian, see Chang et al. (2000: 94-97). For related works by Huang Binhong, see Huang Binhong juewei huaji (1993, plate 12), and Huang Binhong huaji (1992, plate 21).

${ }^{29}$ See Huang Binhong jingpin ji (Zhongguo meishuguan, Renmin meishu chubanshe 2004: 64). Collection of the National Art Museum of China.

${ }^{30}$ See Huang Binhong, 'Guohua zhi min xue,' in Huang Binhong wenji (Shuhua bian, xia) (1999: 451), and Wang Zhongxiu, 'Xunjue 'neimei' de yishu dashi Huang Binhong,' in Mohai botao (1998: 216-17).
} 


\section{Word and Image: The final resting place}

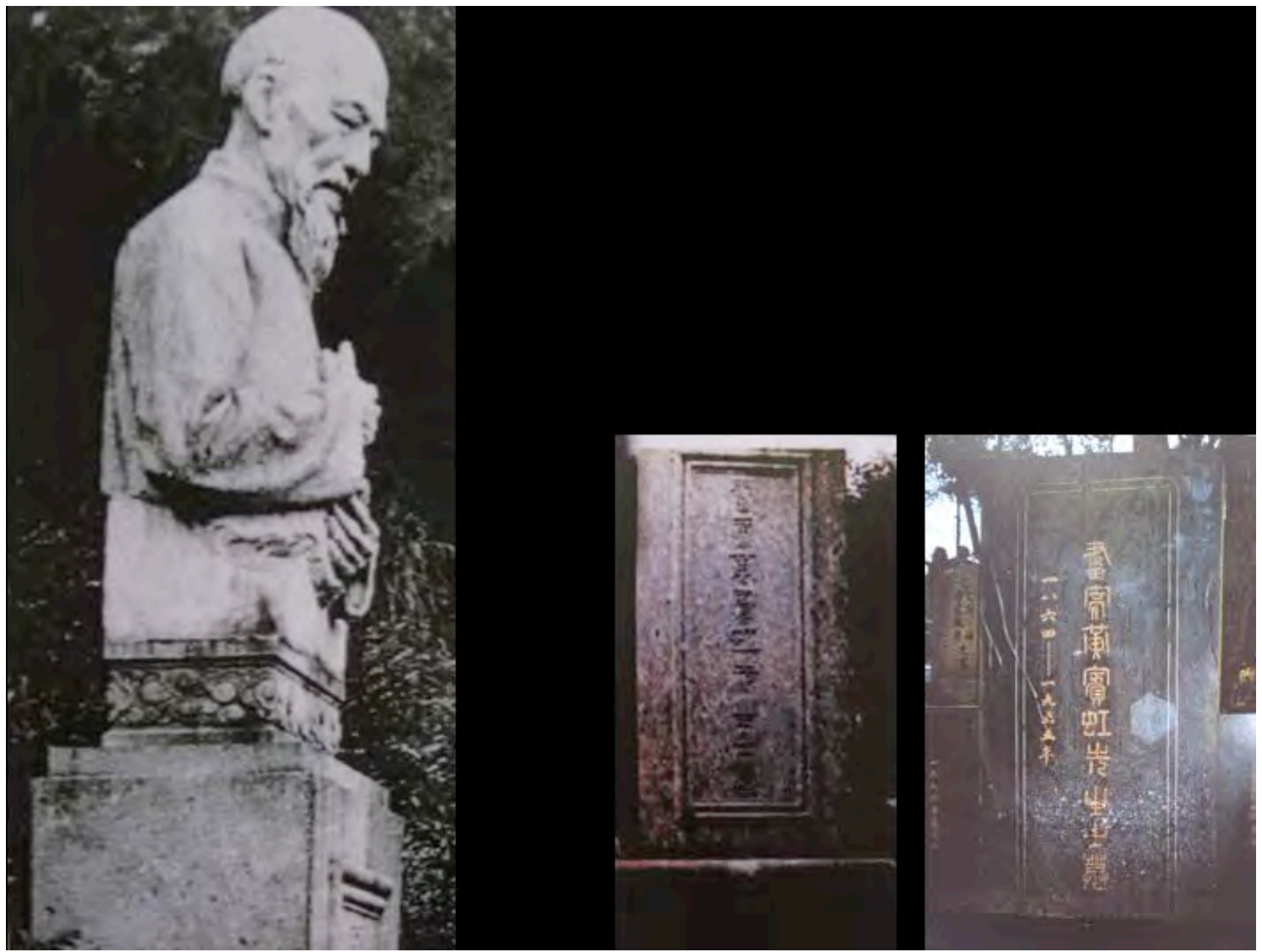

Figure 16: Huang Binhong's grave: grave sculpture and new headstone.

[Grave sculpture reproduced in Wang Zhongxiu (ed.), Huang Binhong nianpu (2005: 560-61); new headstone photographs (C) Claire Roberts]

Huang Binhong is buried in the Nanshan Cemetery in Hangzhou. The original tombstone that marked his grave incorporated a carved torso of the artist wearing a traditional gown, his head bowed and hands clasped to his chest, holding a book. The grave was desecrated during the Cultural Revolution and the sculpture smashed. Today a sombre black granite headstone has replaced the original. It is engraved with the words 'Artist Huang Binhong's Grave 1864-1955' (Huajia Huang Binhong xiansheng $z h i m u$ 畫家黃賓虹先生之墓). The Seal script inscription was copied from the original grave marker, written by Pan Tianshou (潘天寿 1897-1971) a fellow artist and academy professor who died in 1971 as a result of his suffering during the Cultural Revolution.

Today, a bronze statue of Huang Binhong has been erected on the bank of West Lake in Hangzhou, not far from Huang Binhong's former house, now a house museum administered by the Zhejiang Provincial Museum. The statue by Liu Jieyong (劉傑勇) dates from 2000 and is based on a photograph of Huang Binhong sketching near West 
Lake en-plein-air. The use of an image that depicts the artist sketching from life, or to use the parlance of the day 'seeking truth from facts', reflects a desire, perhaps, to better align Huang Binhong with the title bestowed on him in 1953, 'Outstanding Artist of the Chinese People,' in the hope of redefining him as a people's artist, rather than the scholar-artist that he was.

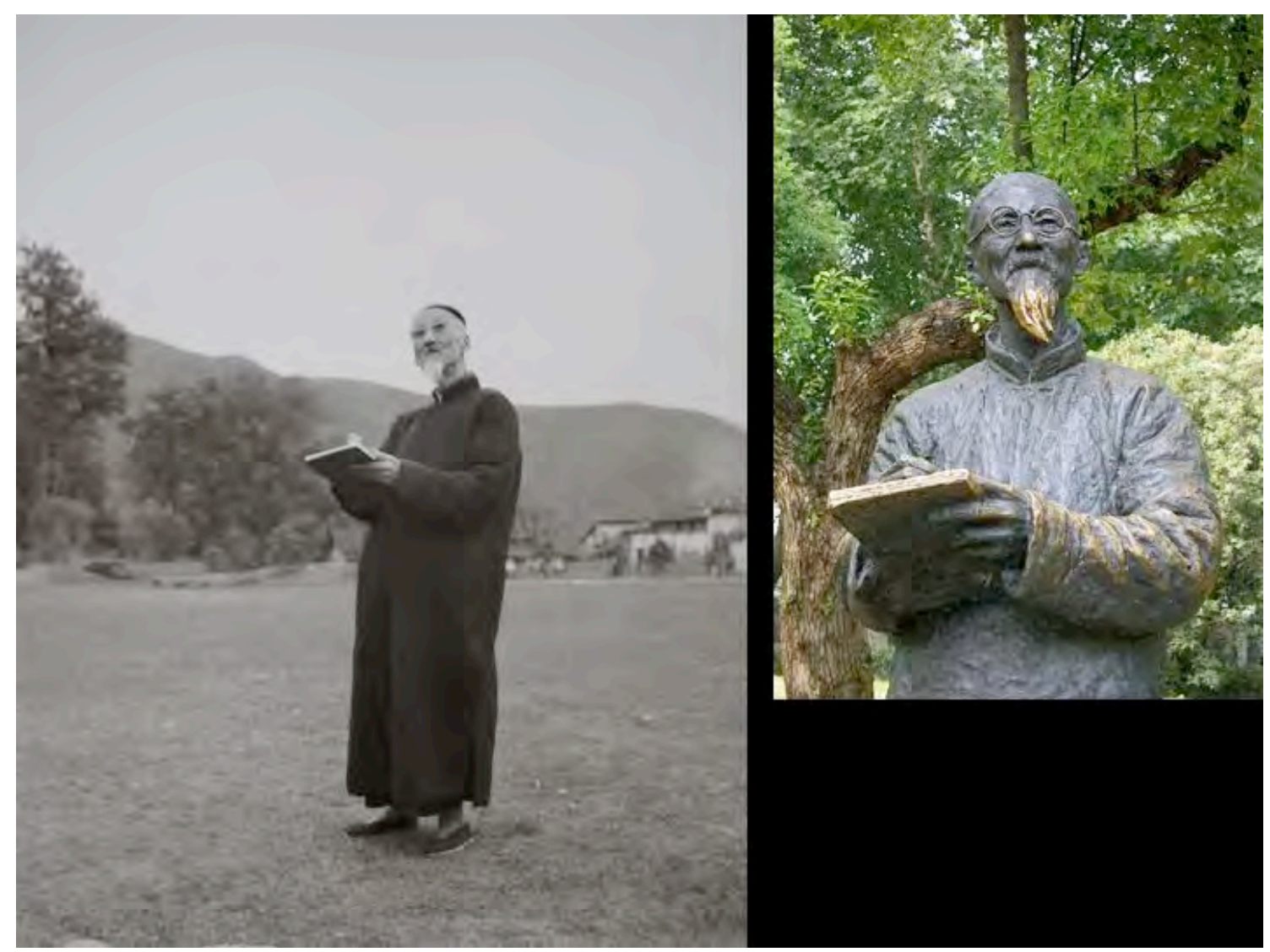

Figure 17: Photograph of Huang Binhong sketching and contemporary bronze sculpture.

[Photograph of Huang Binhong sketching reproduced in Huang Binhong quanji (2006: vol. 10, 289; photograph of bronze sculpture (C) Claire Roberts]

\section{Reference list}

Barmé, G. R. 2002, An Artistic Exile: a Life of Feng Zikai (1898-1975). University of California Press, Berkeley.

Berliner, N. 2003, Yin Yu Tang: The Architecture and Daily Life of a Chinese House. Tuttle Publishing, Boston.

Cahill, J. (ed.) 1981, Shadows of Mount Huang: Chinese Painting and Printing of the Anhui School. University Art Museum, Berkeley.

Chakrabarty, D. 2004, 'Romantic Archives: Literature and the Politics of Identity in Bengal', Critical Inquiry, vol. 30, no. 3 (Spring): 654-682.

Chang, J., Lawton T., \& Allee, S. T. 2000, Brushing the Past: Later Chinese Calligraphy from the Gift of Robert Hatfield Ellsworth. Freer Gallery of Art, Smithsonian Institution, Washington D.C.

Huang Binhong. 1997, Huangshan xiesheng ce. Shanghai huabao chubanshe, Shanghai.

Huang Binhong quanji bianji weiyuanhui (ed.) 2006, Huang Binhong quanji. 10 volumes. Shandong meishu chubanshe, Jinan and Zhejiang renmin meishu chubanshe, Hangzhou.

Huang Binhong yanjiu hui (ed.) 1998, Mohai botao: Huang Binhong yanjiu lunwenji. Xiaoshan wenlian, Xiaoshan. 
Hummel, A.W. 1943, Eminent Chinese of the Ch'ing Period (1644-1912). Library of Congress, Washington, DC.

Kobayashi, H. \& Sabin, S. 1981, 'The Great Age of Anhui Printing,' in Shadows of Mount Huang: Chinese Painting and Printing of the Anhui School, ed. J. Cahill. University Art Museum, Berkeley: 25-32.

Liu Guoxin, Liu Shao, \& He Ruimin (eds) 1994, Zhonghua renmin gongheguo lishi changbian, vol. 1. Guangxi renmin chubanshe, Nanning.

Mao Zedong. 1978, Mao Zedong shici moyi. Wenwu chubanshe, Beijing.

Qiu Zhuchang. 1985, Huang Binhong zhuanji nianpu hebian. Renmin meishu chubanshe, Beijing.

Roberts, C. 'Questions of Authenticity: Huang Binhong and the Palace Museum,' China Heritage Quarterly no. 10 (June). Online, available:

http://chinaheritagenewsletter.anu.edu.au/scholarship.php?searchterm $=010 \mathrm{HBH}-$ Palace.inc\&issue $=010$ [Accessed 1 November 2012].

2010, Friendship in Art: Fou Lei and Huang Binhong. Hong Kong University Press, Hong Kong.

Shan Guolin. 1998, 'Painting of China's New Metropolis: The Shanghai School, 1850-1900,' in $A$ Century in Crisis: Modernity and Tradition in the Art of Twentieth Century China, (eds) J. F. Andrews \& S. Kuiyi. Guggenheim Museum Publications, New York: 20-34.

Shanghai shuhua chubanshe, Zhejiangsheng bowuguan (eds) 1999, Huang Binhong wenji, 6 volumes. Shanghai shuhua chubanshe, Shanghai.

Wang Zhongxiu. 1998, 'Xunjue 'neimei' de yishu dashi Huang Binhong,' in Mohai botao: Huang Binhong yanjiu lunwenji, (ed.) Huang Binhong yanjiu hui. Xiaoshan wenlian, Xiaoshan: 216-17.

Wang Zhongxiu (ed.) 2005, Huang Binhong nianpu. Shanghai shuhua chubanshe, Shanghai.

Wong Yan Ching \& Yau Hok Wa (eds.) 2000, Zhongguo lidai xiyin yishu (The Art of Chinese Seals Through the Ages). Zhejiangsheng bowuguan, Hangzhou and Xianggang Zhongwen daxue wenwuguan, Hong Kong.

Wu Lixia. 2003, Zoujin Huizhou. Huaxia chubanshe, Beijing.

Yetts, P. W. 1933, 'The Shang-Yin Dynasty and the An-yang Finds,' Journal of the Royal Asiatic Society, July: $657-85$.

Yu Jianhua (ed.) 1989, Zhongguo meishu jia renming cidian. Shanghai renmin meishu chubanshe, Shanghai.

Yu Shasong (ed.) 1988, Jinshi shuhua hedingben (yi, er, san, si ce). Hangzhou guji shudian, Hangzhou.

Zhejiang renmin meishu chubanshe, Shanghai renmin meishu chubanshe (ed.) 1985, Huang Binhong hua ji. Zhejiang renmin meishu chubanshe, Shanghai renmin meishu chubanshe, Hangzhou \& Shanghai.

Zhejiangsheng bowuguan (ed.) 1992, Huang Binhong huaji. Shanghai shuhua chubanshe, Shanghai. (ed). 1993, Huang Binhong juewei huaji. Shanghai shuhua chubanshe, Shanghai.

Zhongguo meishuguan, Renmin meishu chubanshe (eds) 2004, Huang Binhong jingpin ji. Renmin meishu chubanshe, Beijing.

Zhongnanhai huace bianji weiyuanhui (ed.) 1993, Zhongnanhai canghua ji. Xiyuan chubanshe, Beijing.

Zhongyang dang'an guan (ed.) 1984, Mao Zedong shou shu gu shici xuan. Wenwu chubanshe, Dang'an chubanshe, Beijing. 